\title{
Por un «materialismo de la relación». Una lectura de Pájaros en la boca de Samanta Schweblin
}

\author{
LORENA FIORETTI Universidad Provincial de Córdoba, Argentina / lorenfio@hotmail.com \\ GABRIELA MANINI Universidad Nacional de Cuyo, Argentina / gabrielamanini@hotmail.com
}

\section{Resumen}

Proponemos trabajar en este texto la escritura de la argentina Samanta Schweblin. Sostenemos que es posible leer en su apuesta narrativa un modo de comprender lo que llamaremos un «materialismo de la relación» como un materialismo que surge del encuentro de la propuesta althusseriana y la derridiana en torno a la cuestión del materialismo no dialéctico. A partir de la articulación con el libro de cuentos Pájaros en la boca (2018) como un «espacio textual», es decir, como un recorte territorial, no una dirección teórica, sino ideológica, histórica y genealógica, pretendemos ensayar una lectura sintomal, pero también deconstructiva, que trabaje desde este materialismo relacional en la pregunta por la relación entre arte y política. Entendemos que desde esta lectura materialista el modo de articulación entre arte y política se sostiene en el trabajo particular con la letra, en los modos en que la trama conjura contra los códigos y las representaciones que este genera alrededor de un Sentido (moral, del tiempo, de las figuraciones de la conciencia de los personajes); y, correlativamente, en su efecto, en lo que la estructura de la pieza literaria pone en movimiento como resonancia en su rechazo a ser un comentario especular y mistificador el mundo.
Palabras clave: materialismo / literatura / Louis

Althusser / Jacques Derrida / Samanta Schweblin

\section{For a «materialism of the relation». A reading of Pájaros en la boca by Samanta Schweblin}

Abstract

In this paper we propose an approach to the writing of the Argentine writer Samanta Schweblin. We consider that it is possible to read in her narrative bet a way of understanding what we will call a «materialism of the relation", a materialism that arises from the encounter of the Althusserian and Derridian proposals around the question for non-dialectical materialism. In articulation with the book Pájaros en la boca (2018) as a «textual space» - that is, as a territorial cut, not a theoretical direction, but ideological, historical and genealogical — we pretend to produce a symptomatic but also deconstructive reading that works from this relational materialism in the question of articulation between art and politics. From this materialist reading, we think, the mode of articulation between art and politics is sustained in the particular work with the literary letter. This is, in the ways that the plot conjures against the codes and its representations around a Sense (moral, time, of the figurations of

Recibido: 1/3/2020. Aceptado: 4/4/2020

Para citar este artículo: Fioretti, L. y Manini, G. (2020). Por un «materialismo de la relación». Una lectura de Pájaros en la boca de Samanta Schweblin. El taco en la brea, 11 (diciembre-mayo), 133-142. Santa Fe, Argentina: UNL. DOI: 10.14409/tb.vii11.9162 
the conscience of the characters). But also, and correlatiKey words: materialism / literatura / Louis Althusser / vely, it is sustained in its effect, in what the structure of Jacques Derrida / Samanta Schweblin the literary piece mobilizes, as resonance, in its refusal to be a specular and mystifying comment on the world.

Una estación llena de gente alegre, repleta de artículos de oficina y probablemente repleta de cambio. Una mancha que ha sido para ellos un sitio de amargura y miedo y que sin embargo ahora, imaginan, se asemeja a la civilización alegre de la Capital. Una última sensación, común a todos, es el espanto: intuir que, al llegar a destino, ya no habrá nada.

Samanta Schweblin, Hacia la alegre civilización

El espacio literario es no solo el de una ficción instituida, sino el de una institución ficticia que en principio le permite a uno decirlo todo. Decirlo todo es, sin duda, reunir, a través de la traducción, todas las figuras en una, totalizar formalizando, pero decirlo todo es también franquear [franchir] prohibiciones. Liberarse [s'affranchir] uno mismo — en todos los campos en que la ley puede hacer a la ley. La ley de la literatura tiende, en principio, a desafiar o a anular la ley. Eso permite, por consiguiente, pensar la esencia de la ley en la experiencia de ese «todo por decir». Es una institución que tiende a desbordar la institución. Jacques Derrida, Esa extraña institución llamada literatura

Estas páginas, a su modo torpe y ciego, ¿No serán esa pieza desconocida (...) continuando en mí su sentido inacabado, buscando en mí, a pesar de mí, en todos los actores y decorados, para siempre abolidos, el advenimiento de su discurso mundo?

Louis Althusser, Pour Marx

En el presente texto proponemos trabajar la escritura de la argentina Samanta Schweblin. A partir del libro de cuentos Pájaros en la boca (2018) ensayaremos una lectura sintomal, pero también deconstructiva, que trabaje desde este materialismo de la relación los posibles modos de (des)anudamiento entre arte y política. Si la política del texto es el elemento más nítido de la presencia del mismo en el entorno social y la escritura trata con lo negociable de la letra (1997) —que da lugar a la circulación de la mercancía literaria-, Rosa sostiene que establecer a priori una serie de decisiones interesadas o fortuitas es asumir una posición en el trámite de la lectura. Se trata de una lectura materialista que se sostiene en una escritura entendida como marca o más bien como una «insignificancia marcante» que permite el juego de la desviación en donde la paradoja es que la identidad de la marca es también la diferencia que disloca cualquier intento de clausura del sentido. Esta lectura/escritura materialista, que llamaremos de la relación, propone pensar esta no como la unión de dos posiciones previamente constituidas, sino que las mismas serán producidas también como efectos incalculables del acontecimiento de este encuentro. Nuestra hipótesis central es que es posible leer el libro de cuentos Pájaros en la boca (2018) de Samanta Schweblin como una apuesta materialista en la que son las relaciones concretas que se tejen a partir del trabajo con la letra, las que resultan una impugnación al código hegemónico. Se deriva de esta hipótesis 
dos cuestiones que intentaremos abordar: por un lado, la postulación de este materialismo de la relación como un artificio teórico construido a partir del pensamiento derridiano y althusseriano' que se caracterizaría por cierta crítica a la historia de la metafísica: que ha separado al materialismo y al idealismo como posiciones antagónicas, que piensa un tiempo desquiciado como crítica al tiempo cronológico, que (de)construye las fronteras entre el adentro y el afuera, el centro y los márgenes, etc. Un materialismo que hace lugar a lo que hay o ha devenido como devenir necesario de un encuentro de contingentes, postulando la primacía de la relación sobre los elementos que en ella toman consistencia y desplazando la centralidad del Sujeto hacia un proceso sin sujeto que domina su desarrollo, sostenido en el abismo del azar del comienzo y del fin. Donde la centralidad del encuentro opera una crítica a los fundamentos metafísicos sobre el Origen, el Sentido, la Causa, la Razón, o el Fin negando, por lo tanto, que toda teleología sea racional, moral, política o estética (Althusser, 1988 y 2002).

Y, por otro lado, nos interesa auscultar el modo en el que la escritura de Schweblin se inscribe en una forma de pensar la relación arte(literatura) y política como lo político en el arte (Richard, 2018). Consideramos que son las modulaciones de las diversas relaciones con el mundo que propone Schweblin y los efectos que las mismas producen, las múltiples posibilidades donde se deconstruye un modo de pensar un sentido de lo político como apuesta teleológica, cronológica y sistemática. Es justamente en la escritura donde la desjerarquización del sentido sitúa todo lo que pueda decirse de la política en términos de múltiples puro es decir, de mestizo, y aparece así como un fenómeno suplementado por la irrupción de un acontecimiento: no hay un sentido primero ni último verdadero del que se desprenderían otros, sino falta de creencia en el sentido único y un goce en el pluralismo. Pero también en este mismo movimiento se proyecta el trazo como efecto diferido sobre los modos en que arte/literatura se articulan con las formas ilusorias bajo las cuales se organiza el sentido como sentido hegemónico. En concreto, materialismo es también crítica de la ideología.

\section{II}

En Althusser este camino reconduce al interrogante: ¿Qué es leer? con el que el filósofo introduce su lectura filosófica y anti-dogmática de El Capital (2004:20). Desde esta perspectiva, un texto no debe ser pensado solo por lo que lo organiza lógicamente como presunto argumento, sino también por todo lo que desorganiza su orden, por lo que lo debilita, por lo que siempre lo interrumpe. Para Althusser solo puede haber lectura verdaderamente fecunda si se renuncia a una lectura a libro abierto, es decir, al mito idealista de la lectura definido por el doble juego de una escritura como revelación de sentido y de una lectura religiosa que le haría eco en una transparencia epifánica. Se trata de descartar la idea de una lectura inocente que daría inmediatamente el sentido de lo que se escribe y se lee, bajo el presupuesto de que es el propio Logos quien nos habla. Si la lectura no es lineal, hay que desplazar el acento hacia el silencio de los textos, a su incompletud, hacia la dificultad de situar e identificar una problemática explícita en todas sus implicaciones. No hay aquí una metodología de lectura o un protocolo de interpretación, sino el gesto de hacer hablar a una pieza a partir de sus impensados. La limpidez de un texto y la idea de lectura como recepción de un sentido inmediatamente dado como presencia, es una ilusión ideológica donde se juega un vínculo especular que debe ser dislocado. Consideramos que esta estrategia de lectura puede orientar nuestra aproximación al texto literario. Pero además, sostenemos que en los cuentos de 
Schweblin esta dislocación se produce por la propia trama del texto, por su estructura, entendida como una conjunción/relación donde se diluye toda acción e intención de los personajes.

Se trata de una ficción que "no se cuenta cuentos», ${ }^{2}$ donde las figuras del materialismo se realizan en el rechazo a una unidad de tiempo, sentido, o sujeto-personaje que realice las figuras de la dialéctica hacia la reconciliación o la síntesis. Y que, por esto mismo, hace posible la crítica en dos niveles. Por un lado, por lo que esta estructura descentrada permite ver a partir de los desplazamientos que produce una vez abolidas, o desmontadas, las voces que realizarían el movimiento dialéctico hacia una resolución. Es decir, que aun cuando el relato de la pieza sea apropiado por una sola voz, se vuelve imposible tematizar el sentido y las implicancias de la misma en una unidad de conciencia que condense sus ritmos y contradicciones. En algunos cuentos de Schweblin lo que queda como resto es una alteridad sin resolución, que deja ver a través del discurso del drama «una realidad desconcertante que constituye el fondo y espera ser reconocida» (Althusser, 1965:143). Es el recuerdo del hambre en La furia de las pestes. ${ }^{3} \mathrm{O}$ el resto que sostiene la prosperidad en progreso de una familia que tiene en la depresión de uno de sus miembros su condición de existencia, como en Mi hermano Walter. En este relato, la situación se presenta como la posibilidad de un hacer productivo del resto mientras todo siga igual. Nada nuevo debe suceder porque: «su movimiento me resulta insólito, me impide moverme o decir nada (...) por un momento todo me parece confuso. (...) aunque reconozco el alivio, las piernas me tiemblan. Casi siento que podríamos morir» (Schweblin, 2018:98). Se abre aquí, creemos, la pregunta por la relación que sostiene la situación/ posición de cada personaje y la conciencia de que es justamente un modo casi de no relación lo que hace que el sentido produzca ominosamente la vida de cada personaje. En estos casos, la literatura en clave materialista permite tocar la política, darle voz al eludir un vínculo mistificante que niegue su determinación, amparada en «una fascinación, un vértigo, una hipnosis, un disfrute puro» (Althusser, 1997:568).

El segundo nivel, se orienta por el efecto disruptivo de los ritmos narrativos. El libro de cuentos Pájaros en la boca transita por diversos paisajes distópicos en un registro ficcional que se vuelve, en ocasiones, mágico, fantástico o incluso bizarro. Lo distópico no aparece como una sociedad futura y sobretodo no aparece en términos morales. Lo distópico aparecería como un movimiento de escritura deconstructivo en el que se tensan las nociones de común, reciprocidad, identificación, sujeto, de tiempo cronológico en tanto tiempo hegemónico, entre otros; y que a partir de un trabajo singular con el lenguaje hace que lo comunicativo, lo inteligible, lo cronológico se vuelva en la escritura misma, opaco. Y es esta opacidad la que aparece como un resto que resiste a la apropiación del pre-supuesto sentido del texto. Dar pájaros para comer, retrotraer el embarazo para decidir sobre él y finalmente escupir la simiente en el momento del parto, no poder tomar un tren atrapado en una ciudad extraña y desesperadamente hospitalaria, desear beber locamente y encontrar(se) en el camino expuestos a la inevitable situación de ser testigos de una muerte dudosa, transitar la angustia por la duda de haber pisado a la hija-mariposa, una niña-anciana que da una última vuelta en la calesita, agujeros negros... Son algunas de las situaciones-montajes que se narran en este libro de cuentos y que permiten ir deconstruyendo cierta transparencia de los sentidos acerca del amor, los cuidados, la hospitalidad, la locura, la familia, el proyecto de un mundo-ciudad feliz, etcétera.

Desde esta perspectiva, creemos que el libro de cuentos Pájaros en la boca resulta una serie de pequeños ensayos en torno al trabajo con los modos de destotalización/dislocación del sentido 
de las relaciones preestablecidas con el mundo, inaugurando al mismo tiempo otros modos de ligar lo visible y aquello que puede ser dicho produciendo así otro sensorium (Rancière, 2013, 2014, 2016). ${ }^{4}$ La introducción de elementos distorsivos en los relatos desvía, interpela e interrumpe, enrareciendo la lógica dialéctica del sentido y contaminando lo que aparecería en principio como un relativo realismo. La irrupción de un tiempo otro, como el caso de Última Vuelta, Una civilización alegre, Agujeros negros, Conservas o La medida de las cosas, se presenta como tramas complejas en donde, en principio, la contraposición al tiempo hegeliano de síntesis y superación, de contemporaneidad y sucesión es reemplazado por lo que Althusser señala como una no-contemporaneidad estructural, donde por estructural se entiende un tiempo fundamental respecto del cual otros tiempos estarían adelantados o atrasados. En estos cuentos el tiempo está fuera de quicio, out of join, trastocado por acontecimientos fortuitos que en algunos casos hacen que el relato sea relanzado al comienzo, en otros, se concluya antes de comprender, y en otros, aparezca un tejido temporal donde diferentes líneas de tiempo se cruzan y se envuelven sosteniendo el relato. Estos gestos producen efectos de desconocimiento y, por ello, la imposibilidad de una inmediata identificación, lo que genera zonas de vacancia, es decir, chances en donde se articula algo de una decisión y un acontecimiento incalculable, es decir, la conjunción de la posibilidad y el azar, dice Derrida (2016) como reconducción o recomienzo del sentido.

Lo que la ficción literaria actúa en cada cuento produce un descentramiento de la mirada que lee, los ritmos yuxtapuestos de espacios, tiempos y sentidos resisten al gesto especular del reconocimiento ideológico de sí, bajo la figura una unidad que condense el ritmo narrativo. De esta forma - siguiendo un camino balizado por Althusser sobre algunas experiencias del teatro y la pintura, así como en su análisis en torno a la ideología - la literatura en clave materialista funcionaría como una maquinaria con el poder de atraer la conciencia del espectador dentro de su mundo ficticio para dislocarla. El efecto de esta dislocación puede quedar indeterminado o diferido y es entonces, donde juega la posibilidad de otro sentido. Hay aquí una apuesta política singular: el materialismo en la modulación althusseriana implicaría el giro que permite la crítica de la ideología dominante, esto es la forma en que el sentido, los rituales, las prácticas y los discursos, se organizan como ideología dominante.

Schweblin insiste en la pregunta por la condición humana en todo el texto, pero es trabajada particularmente en cuentos como «El hombre-sirena», «Pájaros en la boca», «La medida de las cosas", etc., donde aparecen legitimados-nombrados otros posibles modos de relación entre humanos, y también con lo no humano, que (des)estabilizan lo que esperamos de un cierto hacer común y donde la pregunta por el sujeto descentrado es el efecto de una relación (im)posible en términos de comprensión e identificación con el otro. En el cuento «Pájaros en la boca» (un padre accede finalmente a darle para comer y algo de la economía del don se juega en esta crítica pájaros vivos a su hija) no hay dialéctica posible entre la multiplicidad de figuras de conciencia que se presentan. La decisión del padre no surge como consecuencia de un proceso analítico, sino que un conjunto de imágenes (el pasado como repetición de su imbecilidad ahora, las figuras del psiquiátrico como destino, la mujer barbuda que se lleva ratones a la boca) irrumpe como acontecimientos que no pueden ser conectados entre sí bajo ninguna armonía lógica. No es posible hacer jugar dialéctica alguna y la renuncia a la construcción de un sentido final nos desplaza de la lógica de la intencionalidad a la de relación no dialéctica. Eso es lo que queda suspendido al final del texto. El texto atenta contra el mito de la reconciliación que el lector necesariamente no deja de buscar, el texto 
nos atrae y nos divide eternamente. Entendemos que se dibuja en esta renuncia a la reconciliación o síntesis, un modo de relación más allá de la dialéctica de la comprensión del sentido. En esta misma línea, Derrida (1989) sostiene que toda decisión lejos de pensarse como el momento final de un proceso, siempre tiene que ver con un instante de locura, es decir, con la irrupción de una lógica otra que se anuda como irrupción al tiempo lógico y racional.

\section{III}

El encuentro que proponemos entre Derrida y Althusser en torno a la construcción de una noción ${ }^{5}$ de materialismo de la relación se sostiene no en el intento de homologar sus pensamientos ni en la búsqueda obsesiva de coincidencias sino más bien en pensar que sus posiciones sobre el materialismo resultan una crítica que nos permitiría una relectura de una cierta tradición materialista. Se trata, entonces, de una articulación de resonancias:

donde piezas diferentes se tocan sin confundirse, donde se deslizan, pivotean o basculan una sobre otra (...) sin que este juego mutuo que sigue siendo sin cesar, al mismo tiempo, un juego entre ellas forme la sustancia y la potencia superior de un Todo. Pero aquí la totalidad misma es el juego de las articulaciones. (Nancy, 2001:141)

Y es este juego de articulaciones lo que queremos pensar en este texto como un materialismo de la relación en el intento de ponerle un nombre a ese materialismo en el que piensa Derrida, que no se inscribiría en la dicotomía entre idealismo y materialismo, sino que intentaría pensar un (no) más allá de esta relación. Es decir, un materialismo que no invertiría el privilegio del idealismo sobre lo real, sino que mediante el gesto de pensar el «entre» apostaría a pervertir (Foucault y Deleuze) esta relación. Lo que hay, lo que insiste aunque no sabemos si consiste es la relación incluso como no relación que definiría lo que está en juego, los elementos que la misma compromete (en el que tiene lugar siempre una promesa, no una presencia). Este materialismo se inscribiría a distancia del de la «tradición racionalista un materialismo de la necesidad y de la teleología, es decir, una forma transformada y encubierta de idealismo» (Althusser, 2002:32), se trata de un materialismo de la lluvia por el cual los elementos que se encuentran dan lugar a algo que antes no existía. Si en Althusser se trata de un intervalo, en Derrida la estrategia consiste en postular que «el hueco es el relieve, pero la falta y el excedente nunca pueden estabilizarse en la plenitud de una forma o de una ecuación, en la correspondencia inmóvil de una simetría o de una homología» (Derrida, 1977:45). La misma estrategia deconstructiva (Collazo) encontramos en Althusser al descubrir que «agitar políticamente la filosofía» significa señalar las carencias, el «sonido a hueco» de toda «evidencia», sin negar su forma expresiva como plenitud pero asumiendo que toda plenitud se constituye no a pesar de, sino a condición de sus silencios y sus blancos.

En ambos pensadores, este materialismo se constituiría a partir de una cierta concepción presocrática ligada a un pensamiento del azar y de la suerte, un materialismo de la desviación y de la toma de consistencia (Althusser, 2002; Derrida, 1986); un materialismo que disputa al materialismo histórico el supuesto idealista que lo sostiene muchas veces en la forma de la apropiación del sentido. Así, la teoría del texto derridiana es materialista, si por materia no se entiende una presencia sustancial, sino lo que resiste a la reapropiación, que siempre es idealista. En este sentido, la marca escrita no es la marca sensible, la marca material, sino algo que no se deja idealizar o reapropiar. 
La literatura trata de un modo singular con ese resto inapropiable, con eso que se resiste a la «apropiación del sentido por su estatuto ficcional y que se impone mientras se desdibuja toda pretensión ostentosa de narrar la verdad» (Gerbaudo:145). En la escritura de Schweblin ese resto aparece muchas veces como algo ominoso, es decir, como aquello familiarmente extraño pero al mismo tiempo extrañamente familiar que plantea algo no aprovechable e irrecuperable dentro de las lógicas totalitarias, del sistema de intercambio, incluso del sistema de signos explícitos en disidencia. Frente a estos textos comunicables pero nunca demasiados procesables (Richard, 1994), la literatura vuelve a con-movernos y a invitarnos a permanecer en esa pluralidad tensa de jirones y fragmentos que (se) resisten a la unidad, que guardan y reproducen lo otro como un cuerpo extraño, como una contaminación irreductible del sentido.

En «La obra y el resto (literatura y modos del archivo)» (2010), Dalmaroni parte de la siguiente afirmación: «El arte y la literatura (...) mantienen vínculos especialmente disimétricos y heterocrónicos con cualquier política de la memoria» (9). El crítico señala que si la cultura siempre hace de la literatura una cantera de matrices de memoria (matrices subjetivantes, retóricas, ideológicas, institucionales), la literatura es siempre, a la vez, «el acontecimiento en que esas matrices se destartalan y donde sus ejercicios civilizatorios vacilan, balbucean, enmudecen o se ahogan» (10). En este sentido, Pablo Oyarzun se pregunta si esta relación puede plantearse como lo político del arte, o de lo político en el arte, de la política o políticas del arte, del arte político, acaso. Podríamos partir con Nelly Richard, diciendo que estas preguntas resultan una síntesis de las transitadas en la Historia del Arte luego del giro neo-vanguardista y posvanguardista. En esta línea, Hal Foster sostiene que el arte político no se considera ya como «una representación del sujeto de clase (realismo social) sino como una crítica de los sistemas de representación social (y de su posicionamiento respecto al género, los estereotipos étnicos, etc.) mediante una exploración de la construcción cultural de la subjetividad» (en Richard, 2018:97). Desde esta perspectiva no bastaría ya con denunciar las condiciones económicas de la explotación, sino que es necesario conocer el modo en el que estas condiciones se vuelven ideología que afecta nuestro modo de percibir el mundo. ${ }^{6} \mathrm{Y}$ es en este lugar donde Foster propone detectar las zonas de conflicto para constituir una estrategia que interfiera el código hegemónico y que opera en los márgenes «internos» de la estructura dominante «escribiendo subtextos o contratextos localizados en el revés de la trama de los poderes instituidos» (12). En esta línea, la escritura de Schweblin trabaja con el material del código destotalizando los sentidos hegemónicos. Junto a Richard, se trataría de lo político en el arte donde se deconstruyen las hegemonías de la representación. Estos cuentos, creemos, insisten de diversas maneras en pe(n)sar ${ }^{7}$ sobre el sentido único, estorbando la comunicación como traducción lineal del mismo para señalar críticamente la dimensión histórica, política y filosófica de su construcción.

La relación entre literatura y política no supone relacionar dos series previamente definidas sino trabajar sobre las resonancias, es decir, lo que el texto literario da a leer, o más precisamente, lo que toc ${ }^{8}$ de la pregunta política que en ocasiones se presenta en la forma del límite. Se trata solo de un toque porque hay algo que debe permanecer extraño como resistencia al deseo de apropiación de una lógica y la otra. Se trata de trabajar sobre la relación, sobre el entre que los (des)vincula pero que sin embargo expone una articulación posible. Y en donde lo material de la relación nos deja en una zona de indeterminación, donde la reverberación de lo existente puede mantenerse en una pluralidad irreductible a la Totalidad. Pensar la articulación entre arte y política en la 
escritura de Schweblin desde un materialismo de la relación, supone situarse en esas fisuras, en esas indeterminaciones que perforan singularmente la homogeneidad de todo bloque de representación, abriendo vías de escape por las que la imaginación literaria puede derivar se trata de una deriva, pues no hay programas ni reaseguros en una crítica materialista.

Crítica que, entendemos, se tensa aquí entre la noción de escritura como huella y diferimiento por un lado, y un pensar de la literatura a su sombra, a espaldas del placer imaginario que anuda la belleza creadora y el consumo estético, donde el texto se articula con los ideales y las relaciones sociales para ocupar su lugar en la gran partición política de la confrontación ideológica.

\section{Notas}

1 Entendiendo que en ningún caso se trata de seguir un método sino el gesto que convoca el encuentro entre el pensamiento de Louis Althusser y Jacques Derrida en torno a la cuestión de la lectura y el materialismo no dialéctico. Este encuentro se produciría como un «hacer caer juntas» (Vidarte) sus propuestas para evitar pensar que es posible homologarlas.

2 En su biografía de publicación póstuma, Althusser define al materialismo como «no contarse más cuentos» (1992:161). Traducción nuestra, como en todas las citas consignadas a partir de los siguientes textos en lengua francesa: Athusser $(1965,1992,1995,1997)$.

3 Algo del materialismo althusseriano se juega en esta apuesta, donde la pieza hace lugar a la política al dar cuentas del trasfondo real sobre el que se construyen las formas ilusorias de la conciencia dramática, y que en un lenguaje marxiano remite a las condiciones sociales de existencia.

4 Esta dislocación podría ser pensada también como interrupción del sentido hegemónico como señala val flores: «un gesto de lúdica disidencia en relación con las demandas de los órdenes de visualidad contemporáneos (...) la interrupción sólo se hace visible como acción (sobre la imagen), a través de sus efectos abrasivos, sobre otras superficies, materiales, sentidos» (18). En este sentido la propuesta de flores con relación a interrumpir un texto, aparece como una provocación perversa basada en desenhebrar y discontinuar la cadena lineal y lógica que «hace de la escritura una acción discreta desprendida de un cuerpo de impermeable y remota materialidad» (19).

5 Derrida sostiene en su libro Mal de archivo (1997) una propuesta en reacción a la noción de archivo: «No tenemos un concepto, sólo una impresión, una serie de impresiones asociadas a una palabra. Opongo aquí el rigor del concepto a lo vago o a la imprecisión abierta, a la relativa indeterminación de una noción semejante. (...) Tenemos solamente una impresión, una impresión insistente a través del sentimiento inestable de una figura móvil, de un esquema o de un proceso infinito o indefinido» (37). Tomaremos esta idea de noción a propósito del materialismo de la relación.

6 Para las vanguardias históricas, la apuesta estética consistía en la transgresión de las fronteras entre arte y sociedad partiendo de la idea de que esta es un sistema total y no una suma de prácticas muchas veces contrapuestas donde se juega una lucha de interpretaciones sobre los modos de opresión y resistencia.

7 J.L. Nancy sostiene que «el sentido debe significarse, pero lo que produce el sentido, o el sentido del sentido, si se quiere, no es en verdad otra cosa que "esta libertad vacía, esta transparencia infinita de lo que, en fin, ya no tiene más la carga de tener un sentido" (VI, 79)» (2002:42). Se trata de una manera de pesar sobre el sentido mismo, como una manera de estorbar y de oprimir la comunicación de ese sentido, su posibilidad de significar y de significarse. Esta lectura apunta a la «extraña materialidad de la lengua» que se mantiene en suspenso del sentido, frágil y repetido: «la verdadera lectura avanza sin saber, abre siempre un libro como un corte injustificable en el continuum supuesto del sentido» (43).

8 La noción de tocar en la obra de Jean Luc Nancy es trabajada en el libro El Tocar, J.L. Nancy escrito por Derrida en 2011. En este texto el pensador rastrea el modo en el que el tocar aparece como esa imagen que le permite a Nancy señalar la paradoja que implica este acto, porque cuando tocamos no hacemos más que tocar un límite, cuando se toca se abre un espacio y se hace presente la distancia: el espaciamiento que recuerda que existe una hiancia entre la palabra y aquello que es nombrado por esta, denunciando de esta manera, la no correspondencia lineal. 


\section{Referencias bibliográficas}

Althusser, L. (1965). Pour Marx. Paris: Maspero.

(1987). Filosofía y marxismo. Entrevista por Fernanda Navarro. México: Siglo XXI.

(1992). L'avenir dure longtemps suivi de Les faits. Paris: Stock/IMEC.

(1995). Sur la reproduction. Paris: PUF.

(1997). Sur Brecht et Marx. En Althusser, L. Écrits philosophiques et politiques. T.II. Paris: Stock/IMEC, 561-578.

(2002). Para un materialismo aleatorio. Madrid: Arena Libros.

(2004). Para leer El Capital. Buenos Aires: Siglo XXI.

Badiou, A. (2009). Pequeño manual de inestética. Buenos Aires: Prometeo Libros.

(2012). Condiciones. Buenos Aires: Siglo XXI.

Barthes, R. (2004). Crítica y Verdad. México: Siglo XXI.

Billi, N. (2014). La cosa escrita. Materialismo y lenguaje en Maurice Blanchot. París. Actuel Marx/Intervenciones, (16). https://www. academia.edu/19582988/La_cosa_escrita._Materialismo_y_lenguaje_en_Maurice_Blanchot

Bourriaud, N. (2008). Estética relacional. Buenos Aires: Adriana Hidalgo.

Collazo, C. (2016). Althusser y Derrida. La lectura como intervención política. Décalages, 2, Iss. 1. h7p://scholar.oxy.edu/decalages/ vol2/iss1/17

Dalmaroni, M. (2010). La obra y el resto (literatura y modos del archivo). Telar. Revista del Instituto Interdisciplinario de Estudios Latinoamericanos, (7/8), 9-30.

(2015). Resistencias a la lectura y resistencias a la teoría. Algunos episodios en la crítica literaria latinoamericana. Revista de Teoría de la literatura y Literatura Comparada, 452aF, (12), 42-62.

Derrida, J. (1977). Posiciones. Valencia: Pre-textos.

(1986). Del Materialismo no dialéctico. Entrevista con Kadhim Jihad. Culturas, (69), 3-5. https://redaprenderycambiar. com.ar/derrida/textos/materialismo.htm

- (1989). La escritura y la diferencia. Madrid: Anthropos.

(1997). Mal de archivo (Una impresión freudiana). Madrid: Trotta.

(1998). De la gramatología. España: Siglo XXI.

(2001). La lengua no pertenece. Entrevista con Évelyne Grossman, publicada en la edición que el mensuario Europe

consagró a Paul Celan (año 79, N 861/862, enero/febrero 2001). Traducción de Ricardo Ibarlucía publicada en Diario de Poesía, (58), primavera 2001. https://redaprenderycambiar.com.ar/derrida/textos/celan.htm

- (2011). El tocar, Jean Luc Nancy. Buenos Aires: Amorrortu.

(2016). Psyche. Buenos Aires: La Cebra.

(2017). Esa extraña institución llamada literatura. Una entrevista de Derek Attridge con Jacques Derrida.

Traducción de Vicenç Tuset. BOLETIN/18 del Centro de Estudios de Teoría y Crítica Literaria. https://www.cetycli.org/ cboletines/04e9800998-derrida.pdf

Flores, v. (2017). Interruqciones. Ensayos de poética activista. Córdoba: Editorial Asentamiento Fernseh.

Foucault, M. y Deleuze, G. (1995). Theatrum Philosophicum seguido de Repetición y Diferencia. Barcelona: Anagrama.

Gerbaudo, A. (2008). Literatura, biodegradabilidad y políticas del archivo. Por una teoría en (des)construcción. Revista Filosofía UIS, 7, 214-237.

Nancy, J.-L. (2001). La comunidad desobrada. Madrid: Arena Libros. Traducción de Pablo Perera.

(2002). Un pensamiento finito. Barcelona: Anthropos.

Oyarzun, P. (2005). Perplejidad y barruntos. En Oyarzun, P.; Richard, N. y Zaldivar, C. (Eds.). Artey Política. Santiago de Chile: Editorial Arcis, 13-15.

Rancière, J. (2013). Aisthesis: escenas del régimen estético del arte. Buenos Aires: Bordes Manantial. 
(2014). El reparto de lo sensible. Estética y política. Buenos Aires: Prometeo Libros.

(2016). El Malestar en la Estética. Buenos Aires: Capital Intelectual.

Richard, N. (1994). La insubordinación de los signos: cambio político, transformaciones culturales y poéticas de la crisis. Santiago de Chile: Cuarto Propio.

(Comp.) (2018). Arte y Política 2005-2015. Proyectos curatoriales, textos críticos y documentación de obras. Santiago de Chile: metales pesados.

Rosa, N. (1997). Tratados sobre Néstor Perlongher. Buenos Aires: ARS.

Schweblin, S. (2018). Pájaros en la boca y otros cuentos. Ciudad Autónoma de Buenos Aires: Literatura Random House.

Vidarte, P. (2007). Derriladacan: contigüedades sintomáticas. Sobre el «objeto pequeño j@cques». En Peretti della Rocca, C.; Velasco, E. (Coords.). Conjunciones. Derrida y Compañía. España: Dykinson, 105-136. 